\title{
A Survey on Specialty Competencies of Emergency Nurse Practitioners from 15 Tertiary General Hospitals in Guangdong Province
}

\author{
Huang Xuanjie ${ }^{1}$, Luo Yumei ${ }^{1}$, Wang Jiao ${ }^{1}$, Huang Shaomin ${ }^{1 *}$
}

\begin{abstract}
${ }^{I}$ The Emergency and Disaster Medical Center, The Seventh Affiliated Hospital, Sun Yat-sen University, Shenzhen, China, $518107^{*}$ Huang Shaomin is the corresponding author.Email: huanghsm25@mail.sysu.edu.cn. https://orcid.org/0000-0002-8045-2087
\end{abstract}

Article History Received 20 April 2021 Accepted 25 May 2021 Published 30 June 2021

Cite this Article Huang Xuanjie, Luo Yumei, Wang Jiao, Huang Shaomin. A Survey on Specialty Competencies of Emergency Nurse Practitioners from 15 Tertiary General Hospitals in Guangdong Province [J].Medical Research, 2021.3(2):45-52, http://dx.doi.org/10.6913/MRHK.202106_3(2).0006

Copyright @ 2021 Creative Publishing Co., Limited. All rights reserved. Email:mrhk26640333@ gmail.com

\begin{abstract}
Objective To understand the current situation of emergency nurses' specialty competence and propose improvement strategies accordingly, aiming to provide a reference for the comprehensive enhancement of nurse competency as well as the selection and training of high-level nursing management talents.

Methods Using a self-made questionnaire based on literature review, 266 emergency specialist nurses in 15 tertiary general hospitals in Guangdong Province were surveyed through the questionnaire star.

Results The survey showed that the participants appeared to have a high level of self-confidence and recognition for most indicators, as suggested by a high score (195.46 \pm 23.64$)$, except for the aspect of scientific research ability. The scores of scientific research ability items ranged from 3 to 15 points (the 50th quantile was 9 points), and the score was $10.41 \pm 2.28$ with a median score of 10 , indicating that clinical nurses lacked confidence in scientific research abilities. The results of linear regression analysis suggested that gender, job title, publications in recent 5 years, and whether directly affiliated to a teaching hospital were the influencing factors that affect the competence of emergency nurses.

Conclusions Scientific research ability is the major shortcoming of emergency specialist nurses. The influencing factors that affect nurses' competencies include gender, professional title, publications in recent 5 years and whether directly affiliated to a teaching hospital. Nursing scientific research is the power source of the continuous development of nursing discipline. Therefore, it is recommended that the leaders of healthcare authorities and hospitals should strengthen the training of nursing scientific research and improve the scientific research ability of nurses.
\end{abstract}

Keywords Emergency nurse; Competence; Survey; Scientific research; Healthcare

INTRODUCTION

Competency was first proposed by David McClelland, a psychology professor at Harvard University, in 1973. It refers to the deep-level characteristics of individuals who can distinguish outstanding achievers in a certain job from the general population. It includes any characteristics that can be reliably measured or counted or that can distinguish excellent people from general individuals, such as motivation, traits, 
Huang Xuanjie, et.,al. A Survey on Specialty Competencies of Emergency Nurse Practitioners from 15 Tertiary General Hospitals Medical Research ISSN 2664-0333 eISSN 2664-0341 Volume 3 Issue 2 http://dx.doi.org/10.6913/MRHK.202106_3(2).0006

self-awareness, attitudes, knowledge, and cognitive or behavioral skills ${ }^{[1-3]}$. European and American countries started early in the exploration of nurse training, and their training system now is relatively mature and effective. Most western counties have formulated the core competency standards for specialist nurses, which also covers emergency specialist nurses. The history of specialist nurse training in our country is relatively short. Particularly, in terms of training methods and assessment systems for emergency specialist nurses, it is still in the exploratory stage in China ${ }^{[4]}$. Research by Yan Hongli ${ }^{[5]}$ and others have shown that the current emergency nurses' competency evaluation tools are still not satisfactory at measuring the competence of emergency nurses, and so far a unified emergency specialty nurses competency standard is not available in China.

In this paper, we conducted a questionnaire survey and analyzed the competence of emergency nurses in 15 tertiary general hospitals in Guangdong Province, aiming to provide a reference for the comprehensive enhancement of nurse competency as well as the selection and training of high-level nursing management talents.

\section{MATERIALS AND METHODS}

\section{Research participants}

The nursing staff with the professional title of nurse or above in the emergency department of 15 tertiary A general hospitals in Guangdong Province were selected as the survey subjects and distributed in the form of "questionnaire stars". In the end, 266 valid samples were obtained. There were 62 males and 204 females, 29 aged 20 - 30 years, 193 aged 31 - 40 years, 42 aged 41 - 50 years, and 2 over 50 years. In terms of educational background, there were 2 masters, 244 undergraduates, 19 colleges, and 1 secondary school. There were 183 chief nurses (68.8\%) and 120 emergency specialist nurses (45.1\%).

\section{Questionnaire design}

Relevant literature was searched with the keywords of "competence", "emergency nurse" and "specialist nurse" in CNKI, Wanfang databases, and PubMed respectively, using the literature search method. The retrieved literature was read, screened and analyzed, and a questionnaire was designed based on the literature review.

The questionnaire included general information and survey content. The general information covered 11 aspects, including gender, age, educational background, professional title, working years, clinical positions in departments, management positions in departments, publications in the past 5 years, presiding fund or scientific research project approval in the past 5 years, hospital grade and whether it is affiliated to a teaching hospital. There were 49 items on the survey content, including 1 item on professional ethics, 14 items on professional knowledge and skills, 8 items on related knowledge, 3 items on triage and foresight ability, 2 items on resilience, 1 item on comprehensive analysis ability, 3 items on evaluation of decision-making ability, 2 items on evaluation ability, 1 item on planning ability, 1 item on organization ability, 2 items on self-control ability, 1 item on communication ability, 2 items on coordination ability, 1 item on 
self-adjustment ability, 1 item on learning ability, 3 items on scientific research ability, 2 items on teaching ability and 1 item on personal development. The questionnaire used the Likert 5-level scoring method: 5 points for "strongly agree", 4 points for "agree", 3 points for "general", 2 points for "disagree" and 1 point for "strongly disagree". The lowest score was 49 points, and the highest score was 245 points. The higher score indicated better competency of the nurse.

After the first draft of the questionnaire was completed, the head nurse, the deputy chief nurse and the chief physician of the emergency department of the tertiary hospital in Guangdong Province each conducted two rounds of consultation and discussion section, revised the questionnaire content, and defined professional terms to form a formal questionnaire. Thirty samples were taken for pre-survey, and the statistical software SPSS22 was used to analyze the reliability of the questionnaire. The result showed that Cronbach's $\alpha$ coefficient was 0.969 , which indicated that the questionnaire was reliable.

\section{Questionnaire survey}

Questionnaires were distributed using questionnaire stars, 266 valid questionnaires were retrieved, and the effective recovery rate was $100 \%$.

\section{Statistical analysis}

SPSS22.0 statistical software was used for data analysis. The data were described by frequency, percentage, mean, standard deviation, etc. Linear regression was used to analyze the difference in the scores of emergency nurses with different characteristics on the job competency survey. $\mathrm{P}<0.05$ indicates that the difference was statistically significant.

\section{RESULT}

\section{General information of participants}

Due to the relatively low employment ratio of male nurses, $76.7 \%$ of the survey participants were female (Table 1). Most participants were between 30-40 years old, accounting for $72.6 \%$ of the total population, and the majority of them had undergraduate degrees (91.7\%). Among the professional titles, supervisor nurses accounted for $68.8 \%$, and those with more than 10 years of working experience accounted for $76.7 \%$. Moreover, $88.3 \%$ of the staff held clinical positions in the department, and $20.3 \%$ held management positions in the department. Regarding the publications in the past 5 years, $56 \%$ of nurses had publications, and 44.7\% had published 1-3 articles. Few people presided over funds or scientific research projects, $82.7 \%$ had no scientific research funds or project approval. Among the participants, $61.7 \%$ came from affiliated teaching hospitals.

Table 1. General information of the survey participants $(n=266)$

\begin{tabular}{llcc}
\hline Item & Classification & N & Percentage (\%) \\
\hline Gender & Male & 62 & 23.3 \\
& Female & 204 & 76.7 \\
Age & $20-30$ & 29 & 10.9
\end{tabular}




\begin{tabular}{|c|c|c|c|}
\hline \multirow{6}{*}{ Education background (Degree) } & $30-40$ & 193 & 72.6 \\
\hline & $40-50$ & 42 & 15.8 \\
\hline & $>50$ & 2 & 0.8 \\
\hline & Secondary School & 1 & 0.4 \\
\hline & College & 19 & 7.1 \\
\hline & Undergraduate & 244 & 91.7 \\
\hline \multirow{4}{*}{ Title } & Master & 2 & 0.8 \\
\hline & Nurse & 50 & 18.8 \\
\hline & Supervisor nurse & 183 & 68.8 \\
\hline & Associate chief nurse or above & 33 & 12.4 \\
\hline \multirow[t]{2}{*}{ Working years } & Less than 5 years & 5 & 1.9 \\
\hline & $5-10$ years & 57 & 21.4 \\
\hline \multirow{6}{*}{ Clinical position in the department } & $10-15$ years & 124 & 46.6 \\
\hline & $>15$ years & 80 & 30.1 \\
\hline & None & 31 & 11.7 \\
\hline & Nursing group leader & 86 & 32.3 \\
\hline & Department leader & 29 & 10.9 \\
\hline & Nurse specialist & 120 & 45.1 \\
\hline \multirow[t]{2}{*}{ Management position in the department } & None & 212 & 79.7 \\
\hline & Associate chief nurse & 21 & 7.9 \\
\hline \multirow{6}{*}{ Publications in the past 5 years } & Department head nurse & 21 & 7.9 \\
\hline & Chief nurse & 12 & 4.5 \\
\hline & 0 & 117 & 44 \\
\hline & $1-3$ & 119 & 44.7 \\
\hline & $4-6$ & 24 & 9 \\
\hline & $7-10$ & 4 & 1.5 \\
\hline \multirow{4}{*}{$\begin{array}{l}\text { Presided funds or scientific research } \\
\text { project approval in the past } 5 \text { years }\end{array}$} & $>10$ & 2 & 0.8 \\
\hline & 0 & 220 & 82.7 \\
\hline & $1-2$ & 40 & 15 \\
\hline & $3-4$ & 6 & 2.3 \\
\hline \multirow[t]{2}{*}{ Hospital-grade } & Tertiary hospital & 121 & 45.5 \\
\hline & Tertiary referral hospital & 145 & 54.5 \\
\hline \multirow[t]{2}{*}{ Affiliated to a teaching hospital } & Yes & 164 & 61.7 \\
\hline & No & 102 & 38.3 \\
\hline
\end{tabular}

The specialty competence status of the emergency nurses

As shown in Table 2, with the exception of scientific research ability, participants showed high self-confidence and recognition for most indicators, as indicated by high scores (the Likert 5 score of most items was 4 points or above). However, the scores of scientific research ability items were between 3-15 points, the 50th quantile was 9 points, the score was $10.41 \pm 2.28$, and the median was 10 points, indicating 
that the surveyed nurses lacked confidence in their scientific research ability. These results suggested that although most of the surveyed participants were emergency specialist nurses with a bachelor's degree, their scientific research competence remained to be a shortcoming.

Table 2. The survey scores of all dimensions of emergency nurses' specialty competence

\begin{tabular}{llll}
\hline & & & Average score \\
Item & Item score (Min - Max) & Median score & $\begin{array}{l}\text { (mean } \pm \text { SD) } \\
\text { Professional ethics }\end{array}$ \\
Professional knowledge and skills & $1-5$ & 4 & $4.19 \pm 0.81$ \\
Related knowledge & $14-70$ & 56 & $56.92 \pm 7.41$ \\
Triage and foresight ability & $8-40$ & 31 & $30.72 \pm 4.06$ \\
Resilience & $3-15$ & 8 & $7.97 \pm 1.18$ \\
Comprehensive analysis ability & $2-10$ & 8 & $8.39 \pm 1.10$ \\
Decision-making ability & $1-5$ & 4 & $4.14 \pm 0.72$ \\
Evaluation ability & $3-15$ & 12 & $11.94 \pm 1.79$ \\
Planning capabilities & $2-10$ & 8 & $8.14 \pm 1.18$ \\
Organization ability & $1-5$ & 4 & $3.86 \pm 0.66$ \\
Self-control capability & $1-5$ & 4 & $4.06 \pm 0.65$ \\
Communication ability & $2-10$ & 8 & $8.05 \pm 1.26$ \\
Coordination ability & $1-5$ & 4 & $4.09 \pm 0.70$ \\
Self-adjusting ability & $2-10$ & 8 & $8.31 \pm 1.22$ \\
Learning ability & $1-5$ & 4 & $4.12 \pm 0.67$ \\
Scientific research capacity & $1-5$ & 4 & $4.01 \pm 0.66$ \\
Teaching ability & $3-15$ & 10 & $10.41 \pm 2.28$ \\
Personal development & $2-10$ & 8 & $8.15 \pm 1.13$ \\
Overall score & $1-5$ & 4 & $3.86 \pm 0.82$ \\
\hline
\end{tabular}

Independent factors influencing the specialty competence of emergency nurses

As shown in Table 3, through linear regression analysis, it could be determined that gender, professional title, publications in the past 5 years and whether affiliated to a teaching hospital were the factors influencing the specialty competence of emergency department nurses. Moreover, regarding factors influencing their scientific research competencies, linear regression analysis data showed that gender, age, title, publications in the past 5 years, and whether affiliated to a teaching hospital were independent factors (Table 4).

Table 3. Factors affecting emergency nurses' specialty competence determined by regression analysis

\begin{tabular}{llrlcc}
\hline & & & \\
Item & Classification & $\mathrm{N}$ & $\begin{array}{l}\text { Questionnaire } \\
\text { overall score }\end{array}$ & B value & P value \\
\hline Gender & Male & 62 & $198.66 \pm 29.42$ & -8.44 & 0.013 \\
& Female & 204 & $194.46 \pm 23.64$ & & \\
Title & Nurse & 50 & $188.63 \pm 27.06$ & -8.86 & 0.009 \\
& Supervisor nurse & 183 & $199.18 \pm 22.86$ & & \\
& Associate chief & 33 & $200.80 \pm 26.00$ & &
\end{tabular}


nurse or above

\begin{tabular}{llrrrr} 
Publications in the past 5 & 0 & 117 & $188.28 \pm 25.52$ & 8.80 & $<0.0001$ \\
years & $1-3$ & 119 & $200.96 \pm 20.45$ & & \\
& $4-6$ & 24 & $204.11 \pm 23.52$ & & \\
& $7-10$ & 4 & $233.67 \pm 7.09$ & & \\
Whether affiliated to a & Yes & 164 & $200.21 \pm 26.20$ & 7.53 & 0.009 \\
teaching hospital & No & 102 & $191.95 \pm 19.52$ & & \\
\hline
\end{tabular}

Note: B value, regression coefficient.

Table 4. Factors affecting emergency nurses' scientific research competence

\begin{tabular}{lll}
\hline Item & B value & P value \\
\hline Gender & -0.73 & 0.025 \\
Age & 0.92 & 0.022 \\
Job title & -0.87 & 0.008 \\
Publications in the past 5 years & 1.01 & 0.000 \\
Whether affiliated to a teaching hospital & 0.67 & 0.017 \\
\hline
\end{tabular}

Note: B value, regression coefficient.

\section{DISCUSSION}

Clinical nurse specialists are those who have extensive work experience in a certain clinical nursing field and have advanced professional knowledge and clinical skills. They are expected to provide patients with high-quality nursing services in the long-term clinical nursing practice ${ }^{[6-8]}$. Therefore, the evaluation of their job competence and job satisfaction is critical. As a newly emerging department, the emergency department has been greatly developed in recent years, and various forms of specialized nursing training have been carried out in many centers; yet few studies have been carried out to access the specialty competence of emergency nurses. In this survey, the overall score of $195.46 \pm 23.64$ obtained by the participants suggests that after years of training in emergency training courses, emergency nurses have shown great confidence and have become the major labor resource in the emergency department, serving as the clinical nursing team leader and teaching team. On the other hand, the data also exposed the shortcomings, e.g., the scientific research ability, of nursing staff. The scores of scientific research ability items were $3-15$ points $(10.41 \pm 2.28)$ with the 50 th quantile as 9 points, indicating that clinical nurses lacked confidence in their scientific research ability. The linear regression analysis further revealed that gender, title, publications in the past 5 years, and whether affiliated to a teaching hospital were the independent factors affecting the competence of emergency nurses.

Among the surveyed participants, $89.1 \%$ were nurses over 30 years old, $76.7 \%$ were nurses who had worked for 10 years or more, $91.7 \%$ had a bachelor's degree, $81.2 \%$ were nurses in charge and above, and specialist nurses accounted for $81.2 \% .45 .1 \%$ of the respondents have high educational degrees, high professional titles, and many years of experience, which might be the reason that they showed great 
self-confidence and had a high score in the survey. This result is consistent with the research of Xia $Q i, X u$ Yaru, Mai Zhiqin and others ${ }^{[9-13]}$, in which the data pointed out that age and working years were positively correlated with the job competencies of emergency nurses.

The specialty competence of emergency nurses has also been shown to link to their educational level. The higher the educational level, the better the core competence of specialist nurses. The reason may be that, on one hand, people with advanced education implicates that they are knowledgeable and have good logical thinking, and broad vision. On the other hand, these nurses have more access to nursing-related information and training, which may help with their improvement in practice.

Moreover, Cui Jian et al. ${ }^{[14-15]}$ showed that the high professional title of emergency nurses correlated with the specialty competence, which is consistent with the results of this study. Tertiary hospitals, especially the affiliated hospitals of the medical schools, have higher requirements for professional title evaluation, which requires nurses have strong professional practice skills, communication and coordination skills, and scientific research capabilities. Some hospitals have requirements for the number of publications for promotion. In this study, the number of articles published in the past 5 years and whether they are directly affiliated teaching hospitals are factors that affect nurse survey scores and scientific research scores. The studies by Xiong Fanglei, Wen Jinning et al. ${ }^{[16-17]}$ suggested the overall performance of the specialty competence of emergency specialist nurses in tertiary hospitals is better. This is due to the relatively high selection standards for nurses in tertiary hospitals, where a complete training system and training program for specialist nurses have been established. In addition, gender has also become one of the influencing factors. The possible reason is that, in China, compared to male nurses, female nurses may have more responsibility for the family after they get married or have children.

\section{CONCLUSION}

In summary, the survey score on specialty competence suggests that the training of emergence nurses has made great progress over the years. Nevertheless, scientific research remains to be the major shortcoming of emergency nurses. The influencing factors include gender, age, job title, publications in the past 5 years, and whether affiliated to a teaching hospital. Given that nursing research is the source of motivation for the continuous development of the nursing discipline, it is recommended that health departments and hospital leaders at all levels should strengthen the nursing research training and continuously provide scientific research opportunities to the nurses.

\section{ACKNOWLEDGMENT}

This study was supported by the research grant of the Guangdong Nursing Association (Grant number: gdhlxueh2019zx342).

\section{STATEMENT}

There is no conflict of interest in this article. 
Huang Xuanjie, et.,al. A Survey on Specialty Competencies of Emergency Nurse Practitioners from 15 Tertiary General Hospitals Medical Research ISSN 2664-0333 eISSN 2664-0341 Volume 3 Issue 2 http://dx.doi.org/10.6913/MRHK.202106_3(2).0006

\section{REFERENCES}

1 CORMACK C L, JENSEN E, DURHAM C O, et al. The 360-degree evaluation model: A method for assessing competency in graduate nursing students. A pilot research study [J]. Nurse Education Today, 2018, 64, 132.

2 RAVEN J. Chapter 15: The McClelland/McBer Competency Models [J]. Counterpoints, 2001, 166 (225-236).

3 MCCLELLAND D C, OTHERS A. Pedagogy and Competency-Based Education. Paper No. 3, Series of 6 [J]. Competency Based Education, 1975, 18.

4 Huang Yanmei, Li Yuan, Liu Qiangqiang, et al. Construction of Stratified Training Outline for Emergency Nurses Based on Post Competence [J]. Chinese Journal of Health Emergency, 2017 (5), 308-311.

5 Qi Hongli, Zhang Ling. Comparison of competence evaluation tools for emergency nurses. Chinese People's Liberation Army Journal of Hospital Management. 2020. 27 (10): 993-994.

6 BERGSTR M P, LINDH V. Developing the role of Swedish advanced practice nurse (APN) through a blended learning master's program: Consequences of knowledge organisation [J]. Nurse Forever Pract, 2018, 28 (196-201).

7 NEWHOUSE R. Advanced nurse practice outcomes 1999-2008: A systematic review [J]. Nursing Economic, 2011, 29 (5): 1-22.

8 Karami A, Farokhzadian J, Foroughameri G. Nurses' professional competency and organizational commitment: Is it important for human resource management? PLoS One. 2017;12(11):e0187863. Published 2017 Nov 8. doi:10.1371/journal.pone.0187863

9 Xia Qi, Wen Xianxiu. Research Progress of Core Competence Index of Wound Stoma Nurses [J]. Modern Clinical Medicine, 2016, 42 (4): 313 -317, 320.

10 Lou Yan. Compilation of Core Strength Scale for Community Nurses and Its Reliability Test [J]. Journal of Lishui University, 2018, 40 (5): 88-92.

$11 \mathrm{Xu}$ Yaru. Compilation and Credibility Test of Critical Care Competence Scale for Clinical Nurses [J]. Frontiers in Health, 2018, 27 (6): 108.

12 Mai Zhiqin, Deng Zhizhen, Huang Hailing, et al. Study on the Application Effect of Core Competence Teaching Model in Blood Purification Specialized Nurse Training [J]. China Medical Science, 2017, 7 (7): 38-40.

13 Xie Meichan. Evaluation of the effect of ICU professional nurse core competence training on improving the core competence of specialist nurses [J]. Health Vocational Education, 2017, 35 (19): 116 -117.

14 Cui Jian, Sun Hongyan, Wang Qingzhen. On-the-job training and effect evaluation for neurosurgical specialist nurses [J]. Medical Education Administration, 2016, 2 (3): 548 -552.

15 Yang Xuhong, Dong Min, Zheng Min et al. Application of core competency-oriented advanced curriculum in training of wound stoma nurses [J]. Chongqing Medical Journal, 2018, 47 (12): 1607-1609, 1615.

16 Xiong Fanglei, Liao Qiaocong. Discussion on the training of cancer nurse specialist oriented to the training of core competence [J]. Special Health, 2017, 14 (17): 277.

17 Wen Jinning, Yao Minhong. Establishment of Evaluation Index System for Core Competence of Psychiatric Nurses [J]. China Medical Herald, 2016, 13 (29): 144-148. 